\title{
A viscoelastic model of interseismic strain concentration in Niigata-Kobe Tectonic Zone of central Japan
}

\author{
Mamoru Hyodo ${ }^{1 *}$ and Kazuro Hirahara ${ }^{2}$ \\ ${ }^{1}$ Graduate School of Sciences, Nagoya University, Furo-cho, Chikusa-ku, Nagoya 464-8602, Japan \\ ${ }^{2}$ Graduate School of Environmental Studies, Nagoya University, Furo-cho, Chikusa-ku, Nagoya 464-8602, Japan
}

(Received December 27, 2002; Revised December 16, 2003; Accepted December 16, 2003)

\begin{abstract}
The high strain rates of the Niigata-Kobe Tectonic Zone (NKTZ) of central Japan have been simulated using a viscoelastic nite element model of great interplate earthquake cycles that includes the subducting Paci $\mathrm{c}$ plate and lateral changes in crustal structure beneath NKTZ. As a result of long-term loading at trenches, the elastic crust over a viscoelastic mantle can transfer stress or strain rate not only as an average of geological time scales, but also during an interplate earthquake cycle. Thus, if the earthquake cycle is several times longer than the relaxation time of the viscoelastic system, deformation of an inland area far from trenches responds to the cycles of interplate earthquakes, and the crust deforms like an elastic sheet during the later stage of an earthquake cycle, allowing ef cient transmission of stress during this period. Therefore, in the case of long interplate earthquake cycle, the NKTZ crustal structure with small thickness and rigidity enhances local interseismic strain concentration there. The "plate coupling ratio" $(0.4 \sim 0.5)$ between Paci c and Amurian plates and local crustal heterogeneity beneath the high strain rate zone explain the large strain rate belt if the earthquake cycle offshore Kanto is enough long.

Key words: FEM, NKTZ, interplate earthquake cycles, Paci c plate, crustal structure.
\end{abstract}

\section{Introduction}

Recently, the GEONET (GPS Earth Observation NETwork) operated by the GSI (Geographical Survey Institute) of Japan has revealed that a remarkable zone of high strain rates, called NTKZ (Niigata-Kobe Tectonic Zone), runs from Niigata to Kobe as shown in Fig. 1. Across this zone, high WNW-ESE shortening rates averaging $\sim 10^{-7}$ strain/yr are observed, which are several times as large as those in the surrounding region (Sagiya et al., 2000). The existence of such a high strain rate zone was also indicated by the analyses of triangulation data over the past 100 years (e.g. Hashimoto, 1990; Hashimoto and Jackson, 1993; Ishikawa and Hashimoto, 1999). In addition, within this zone, many Quaternary active faults exist and a number of historical large earthquakes occurred (red and blue circles in Fig. 1). Thus, the high strain rates observed by GPS or triangulation surveys are not temporal but possibly re ect the tectonic loading of the active faults in central Japan. However, the source of the stress or strain loading along NKTZ is an unresolved problem.

This study has also been inspired by the recent work of Iio et al. (2002), who proposed a structural model of stress or strain loading in NKTZ. We examine their model using viscoelastic FEM simulation, and point out, as a mechanism of long-range loading far into the inland, the importance of periods of interplate earthquake cycles at trenches in a

*Present address: The Earth Simulator Center, Showa-machi 3173-25, Kanazawa-ku, Yokohama 236-0001, Japan.

Copy right(C) The Society of Geomagnetism and Earth, Planetary and Space Science (SGEPSS); The Seismological Society of Japan; The Volcanological Society of Japan; The Geodetic Society of Japan; The Japanese Society for Planetary Sciences. viscoelastic medium, in addition to their model.

\section{What is the Source of East-West Compression in Central Japan?}

Huzita (1980) suggested that east-west compressive stress eld in the inland region of central and southwest Japan is caused by the subduction of the Paci c plate (PA) offshore Kanto. Beneath the Kanto district, the Philippine Sea plate $(\mathrm{PH})$ is sandwiched by the subducting PA and overriding Japanese crust (JAP) (see the contour of subducting plates shown in Fig. 2(a)). Thus, the surface deformation should be in uenced by all of PH/JAP, PA/JAP and PA/PH interactions if each plate boundary is locked. Elastic inversion analyses of GPS strain rate data, however, indicate that surface strain rate eld in the Kanto district is tted by only the PH/JAP interaction, and the consideration of elastic coupling between the subducting PA and overriding plates does not explain the surface deformation (Mazzotti et al., 2001; Henry et al., 2001). In addition, there have been no large recent interplate earthquakes associated with the subduction of PA in the Kanto district (dotted red ellipse in Fig. 1). Accordingly, many researchers concluded that the PA offshore Kanto has no contribution to the overriding plates, and that rigid motion of the Kanto district re ects the motion of North American plate (NA) or an inland arc. Hence, NKTZ, which is located far from the trenches, is proposed to be the plate boundary between the Amurian plate (AM) and NA (Heki and Miyazaki, 2001), or a boundary between AM and an island arc (Mazzotti et al., 2000).

However, even in the short-term deformation data such as GPS velocities, inelastic deformation associated with the viscous response of the upper mantle or lower crust must be 


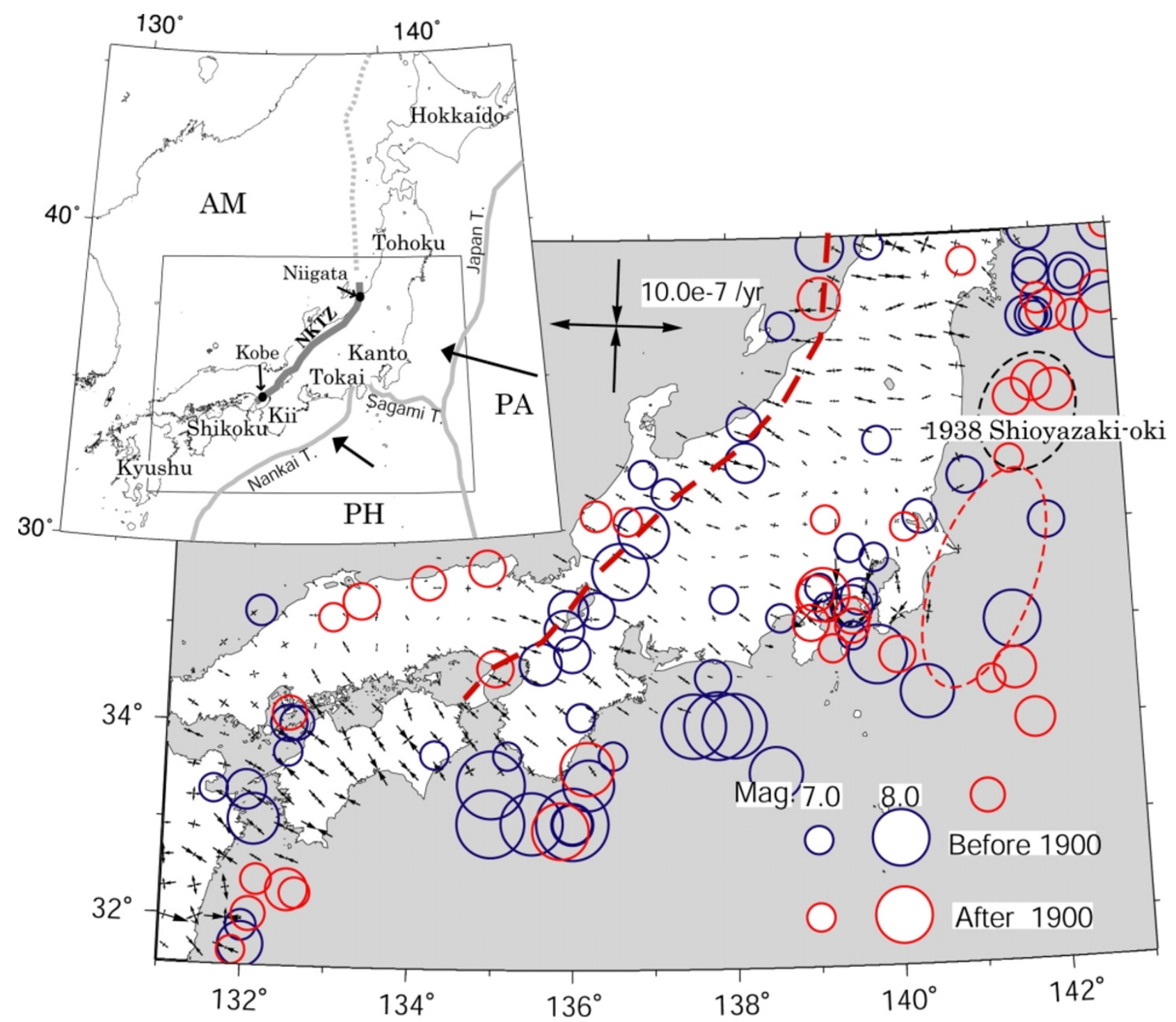

Fig. 1. Distribution of principal axes of horizontal strain rates deduced from continuous GPS observation (February 1996-June 1999). Historical large $(\mathrm{M}>7)$ shallow (depth $<60 \mathrm{~km}$ ) earthquakes in and around southwest and central Japan are also plotted by blue (before 1900) and red (after 1900) circles. The red broken line and the thick gray line in the inset show the high strain rate zone (NKTZ). In the inset, plate tectonic setting in the Japan islands and the district names are also shown, where AM, PA and PH indicates the Amurian, Paci c and the Philippine Sea plate, respectively. The gray lines indicate the major plate boundaries. The rectangle in the inset shows the southwestern and central Japan.

included. Wang and Suyehiro (1999) proposed that the longterm loading of slab push at trenches enables the long-range transmission of stress and creates the stationary stress regime at the inland region, since the asthenosphere is expected to be relaxed in the view of the long-term average. Here in this paper, we discuss the long-range transmission of the present instantaneous strain rate revealed by GPS observations as a result of additional earthquake-cycle effects at trenches. Using viscoelastic FEM model, Wang et al. (2001) simulated interseismic deformation in the Cascadian subduction zone, where the great interplate earthquake cycle is much longer ( $\sim 500$ years) than Tohoku or southwest Japan $(\sim 100$ years $)$, and the last major great interplate earthquake there occurred 300 years ago. Their kinematic modeling shows that the viscoelastic model predicts strain rates consistent with geodetic observations and, in comparison with the results of the elastic models, model strain rates are smaller and distributed in a broader forearc region. Therefore, if the interplate earth- quake cycle offshore Kanto is much longer than that off Tohoku or southwest Japan, the rigid motion and resultant small GPS strain rates in the Kanto district possibly re ect the viscoelastic effects of earthquake cycles at trenches as in case of the Cascadian subduction zone.

Iio et al. (2002) suggested that the lower crust beneath NKTZ might be weakened by the dehydration of the PA slab, and its viscosity is much lower than in the surrounding lower crust. They also suggested a possibility that the effect of the subducting PA signi cantly affects the inland deformation. According to their model, the elastic thickness of the crust beneath NKTZ will be smaller than in the surrounding region. With the assumption of a very long interplate earthquake cycle, concentration of deformation will occur in the NKTZ at a time beyond the relaxation time of viscoelastic system.

In this paper, we assume that the Kanto district belongs to $\mathrm{AM}$, and the relative velocity of $\mathrm{PA} / \mathrm{AM}$ is $9 \mathrm{~cm} / \mathrm{yr}$ with 
(a)FEM mesh at the surface

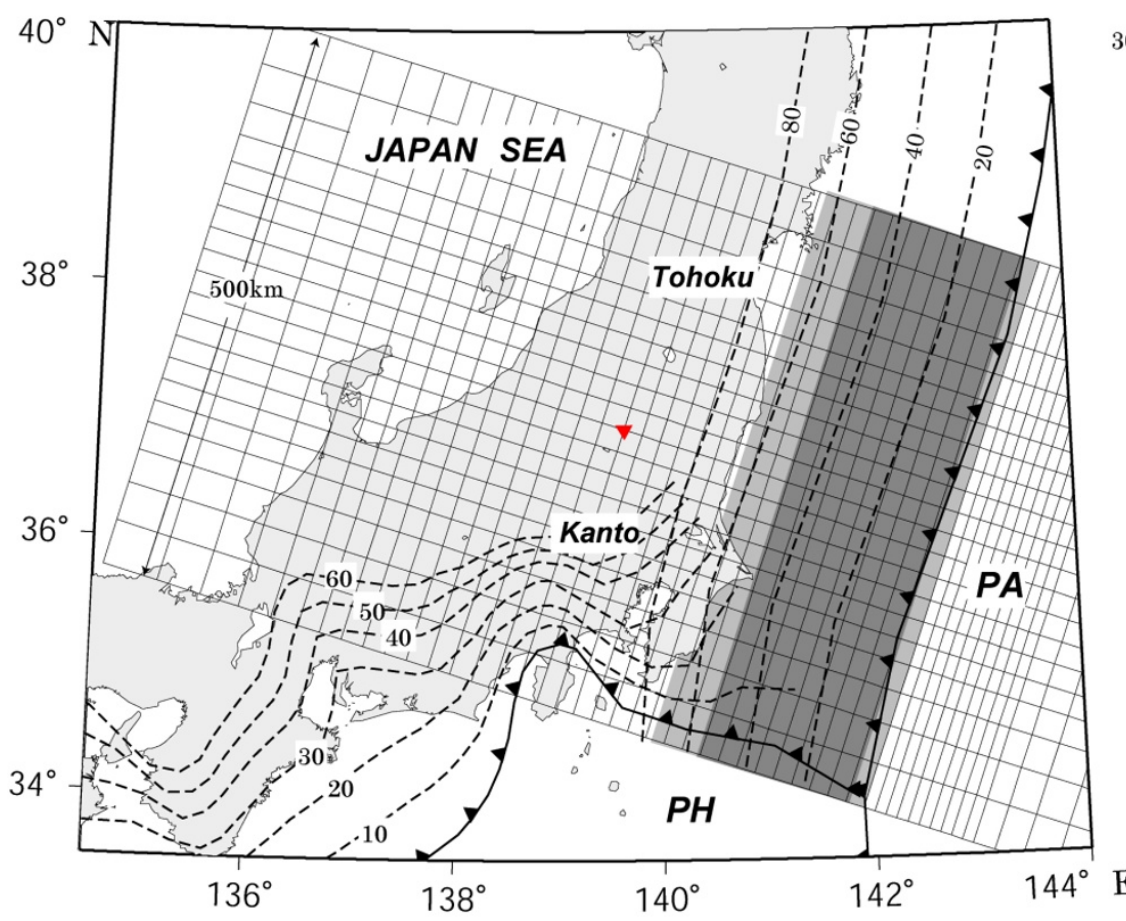

(b) Uniform model (thickness of the crust $=30 \mathrm{~km}$ )

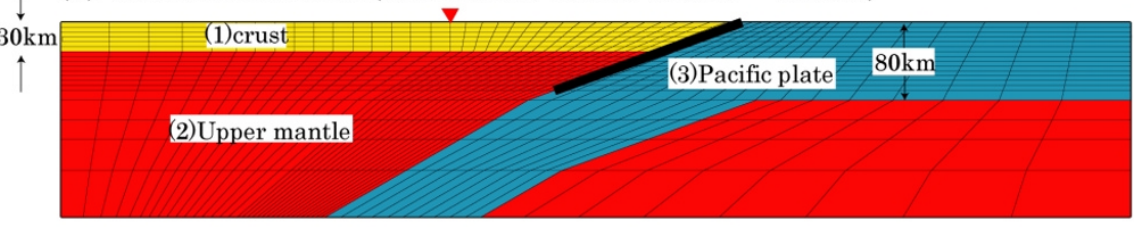

$1100 \mathrm{~km}$

(c) Model 1 (Viscoelastic lower crust $=15 \mathrm{~km}$ )

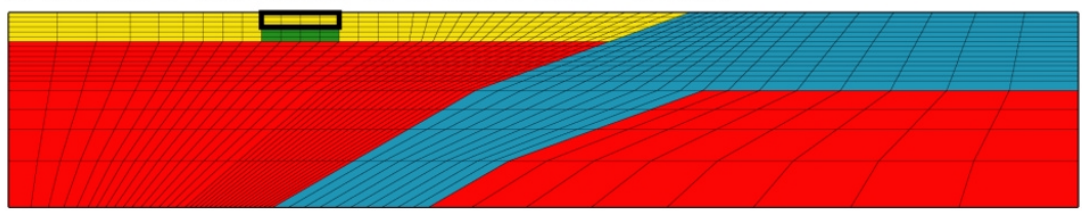

(d) Model 2 (Viscoelastic lower crust $=25 \mathrm{~km})$

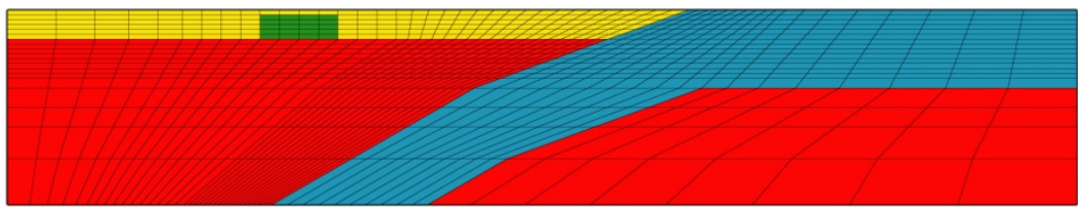

Fig. 2. FEM mesh used in this study. (a) Horizontal view of the FEM mesh in central Japan. The dark and light shaded rectangles represent the full and transient coupling zone, respectively. (b) Vertical cross section of FEM mesh with the uniform crustal structure along the WNW-ESE direction. The bold line indicates the coupling region. (c) and (d) Vertical cross sections of FEM models including the heterogeneity in the crustal structure beneath NKTZ. The thickness of the upper crust beneath NKTZ is (c) $15 \mathrm{~km}$, and (d) $5 \mathrm{~km}$. 

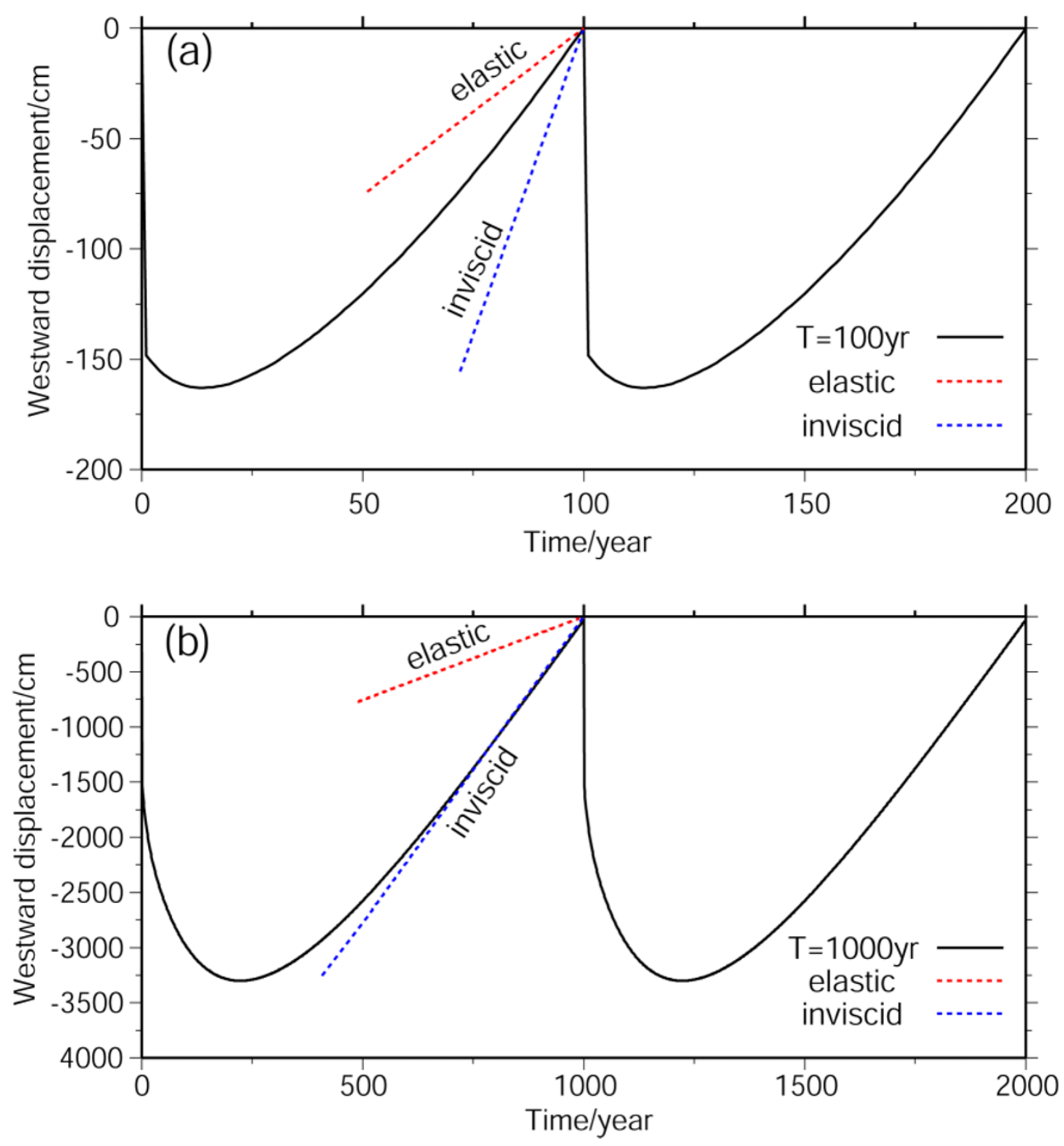

Fig. 3. Temporal change in horizontal motions at a site in the inland region, whose location is shown by a red triangle in Fig. 2 , during the earthquake cycles with different periods, $T$, (a) $T=100$ years, and (b) $T=1000$ years. The dotted red line and blue lines indicate the results in the purely elastic mantle and the inviscid mantle, respectively.

a direction of $\mathrm{N} 80^{\circ} \mathrm{W}$. Then, we evaluate the effect of the following four parameters on the interseismic deformation eld in central Japan using a viscoelastic 3-D FEM code, GeoFEM (Iizuka et al., 2002),

- the period of earthquake cycle

- the thickness of lower crust beneath NKTZ

- the rigidity of upper crust beneath NKTZ

- the "plate coupling ratio" between PA/AM,

and compare the observed velocity eld with the calculated one. Here, we de ne the "plate coupling ratio" is a proportion of "backslip" (see the Section 3.2) rate versus relative plate velocity at the subduction fault. In the general kinematic framework, the seismic slip periodically occurs and its slip amount is equivalent to the accumulated "backslip" during an earthquake cycle. In such a case, "plate coupling ra- tio" is equal to the ratio of seismic versus total (aseismic) slip of the subduction fault during an earthquake cycle, which is so-called "seismic coupling ratio".

\section{Model Characteristics}

\subsection{FEM model}

Figure 2 shows our three-dimensional FEM model in central Japan. There, we adopt iso-parametric hexahedral elements with eight nodes (Zienkiewicz and Cheung, 1967). The total numbers of nite elements and nodes used here are 19,760 and 22,260 , respectively. The size of the model is $1,100 \times 500 \times 200 \mathrm{~km}$. In constructing the model, we take into account the subducting PA which has a thickness of $80 \mathrm{~km}$, a dip angle of $20^{\circ}$ in the shallow seismogenic zone $(0 \sim 80$ $\mathrm{km}$ ), and a slightly steep dip angle of $30^{\circ}$ at the deeper portion. For simplicity, we ignore the structural change along the Japan trench. Thus, our FEM model is almost the same one as two-dimensional model. The crust and the subduct- 
Table 1. Material properties used in this study. These values are quoted from Sato et al. (1981) and Suito and Hirahara (1999). The numerals in the rst column correspond to the sub-regions described in Fig. 2(b).

\begin{tabular}{lcccc}
\hline & $\begin{array}{c}\text { Rigidity } \\
(\mathrm{Pa})\end{array}$ & $\begin{array}{c}\text { Poisson's } \\
\text { ratio }\end{array}$ & $\begin{array}{c}\text { Viscosity } \\
(\mathrm{Pa} \mathrm{s})\end{array}$ & $\begin{array}{c}\text { Relaxation } \\
\text { Time }(\mathrm{yr})\end{array}$ \\
\hline (1) Crust & $3.3 \times 10^{10}$ & 0.23 & $\infty$ & $\infty$ \\
(2) Upper Mantle & $5.9 \times 10^{10}$ & 0.27 & $9.3 \times 10^{18}$ & 5.0 \\
(3) Paci c Plate & $1.9 \times 10^{11}$ & 0.26 & $\infty$ & $\infty$ \\
\hline
\end{tabular}

ing PA are purely elastic, and the upper mantle is assumed to be a Maxwell viscoelastic body with a relaxation time of 5 years (Suito and Hirahara, 1999). The material properties are tabulated in Table 1. We assume that the model surface is stress-free, and the other ve outer boundaries can have slip components parallel to the planes. In this FEM model, the interplate earthquake cycles of PA is described by "backslip" model as described in the following section, and the dislocation is transformed to the equivalent nodal force using the split node technique (Melosh and Raefsky, 1981).

3.2 Modeling of the subduction of PA and great interplate earthquakes

In the kinematic framework of earthquake cycle modeling, the interaction of two plates along the convergent plate boundary during the interseismic period is understood as the superposition of the steady state subduction and the virtual normal slip on the seismogenic zone, which is generally called "backslip" (Savage, 1983). The "backslip" smaller than the plate convergence velocity means the fault is not completely locked but is slipping at a rate lower than the plate convergence rate as a part of the steady slip component. For a relatively short-term deformation including several earthquake cycles, we can approximate the changes in crustal deformation during the interseismic period only by applying "backslip" on the main thrust zone, because the steady slip contributes to the long-term deformation. The "backslip" accumulated during the interseismic period is periodically released as great interplate earthquakes there. As previously mentioned, the elastic inversion analysis of Mazzotti et al. (2001) does not require the coupling between PA and AM (or JAP). Nevertheless, we include PA/AM locking into our viscoelastic FEM analysis. We assume the distribution of the locking on the plate interface is the same as that of Tohoku district used by Mazzotti et al. (2000), which has the lower limit of the fully locked zone at a depth of $55 \mathrm{~km}$, with a transition zone down to $70 \mathrm{~km}$, as indicated by a shaded rectangle in Fig. 2(a), and by a bold line in Fig. 2(b).

\section{Results and Discussions}

\subsection{Effect of the period of earthquake cycles}

First of all, we consider the effect of the period of earthquake cycle, $T$, on the deformation in the inland region. Figure 3 shows the temporal changes of horizontal displacement during earthquake cycles with two different periods $T$ in a position in the inland area indicated by a red triangle in Figs. 2(a) and 2(b), together with those in the purely elastic and inviscid mantle cases. In the Tohoku area, the period of the earthquakes cycle is about 100 years or shorter, for example, the earthquake cycles offshore Miyagi Pref., southern Tohoku, is estimated to be about 40 years (Ohtake,
1999). In this case, the response in the inland region to the earthquake cycle of PA is nearly the same as the elastic case indicated by the dotted red line in Fig. 3(a). In this FEM model, as a whole system, the response to the step dislocation on the plate interface decays with a relaxation time of several hundred years. For $T=100$ years, the deformation associated with earthquake cycles is not very different from the result in the purely elastic case during the entire cycle, since $T$ is enough shorter than the relaxation time of viscoelastic structure. Figure 4(a) shows the horizontal velocity pro les at the surface in the distance from the Japan Trench. The solid blue line with solid squares indicates the velocity pro le at 60 years after the occurrence of the previous earthquake ( $T=100$ years), and the dotted blue one shows the pro le in the purely elastic model. The comparison of these two pro les con rms that the deformation velocity of inland region is almost approximated by the purely elastic model if the earthquake cycle is shorter than the relaxation time of a whole system. As a most suitable contemporary velocity pro le in Tohoku, we choose the velocity pro le at 60 years after the occurrence of the previous earthquake, since the most recent great interplate earthquakes in southern most Tohoku is the 1938 Shioyazaki-oki earthquakes $\left(\mathrm{M}_{\mathrm{w}} \sim 7\right)$ as shown in Fig. 1.

On the other hand, in the case of $T=1000$ years in Fig. 3(b), the deformation during the later stage (900 years after the occurrence of the previous great earthquake) of a cycle is similar to that in the inviscid mantle indicated by the dotted blue line in Fig. 3(b), because $T$ is enough longer than the relaxation time of the viscoelastic structure. In the later stage of earthquake cycle, the horizontal velocities due to the PA/AM interaction have larger values in the inland area far from the Japan Trench and the effect of the interaction extends far into the inland area as shown by the red line with open diamonds in Fig. 4(a), comparing with the one with $T=100$ years in Fig. 4(a). This is caused by the fact that the asthenosphere loses its rigidity to resist the elastic coupling and only the elastic crust resists it for the loading longer than the relaxation time. In the case of $T=1000$ years, the horizontal component of surface velocities linearly decreases from the trench to the inland region, hence the surface strain rate is almost constant. Namely, the crust deforms like an elastic sheet, since the crust and mantle are decoupled in the later stage of each earthquake cycle.

\subsection{Effect of the heterogeneous structure beneath NKTZ}

The results of the previous section indicate that the crust deforms like an elastic sheet if the period of an earthquake cycle, $T$, is much longer than the relaxation time of the viscoelastic structure. Hence, if the lower crust beneath NKTZ 
(a)

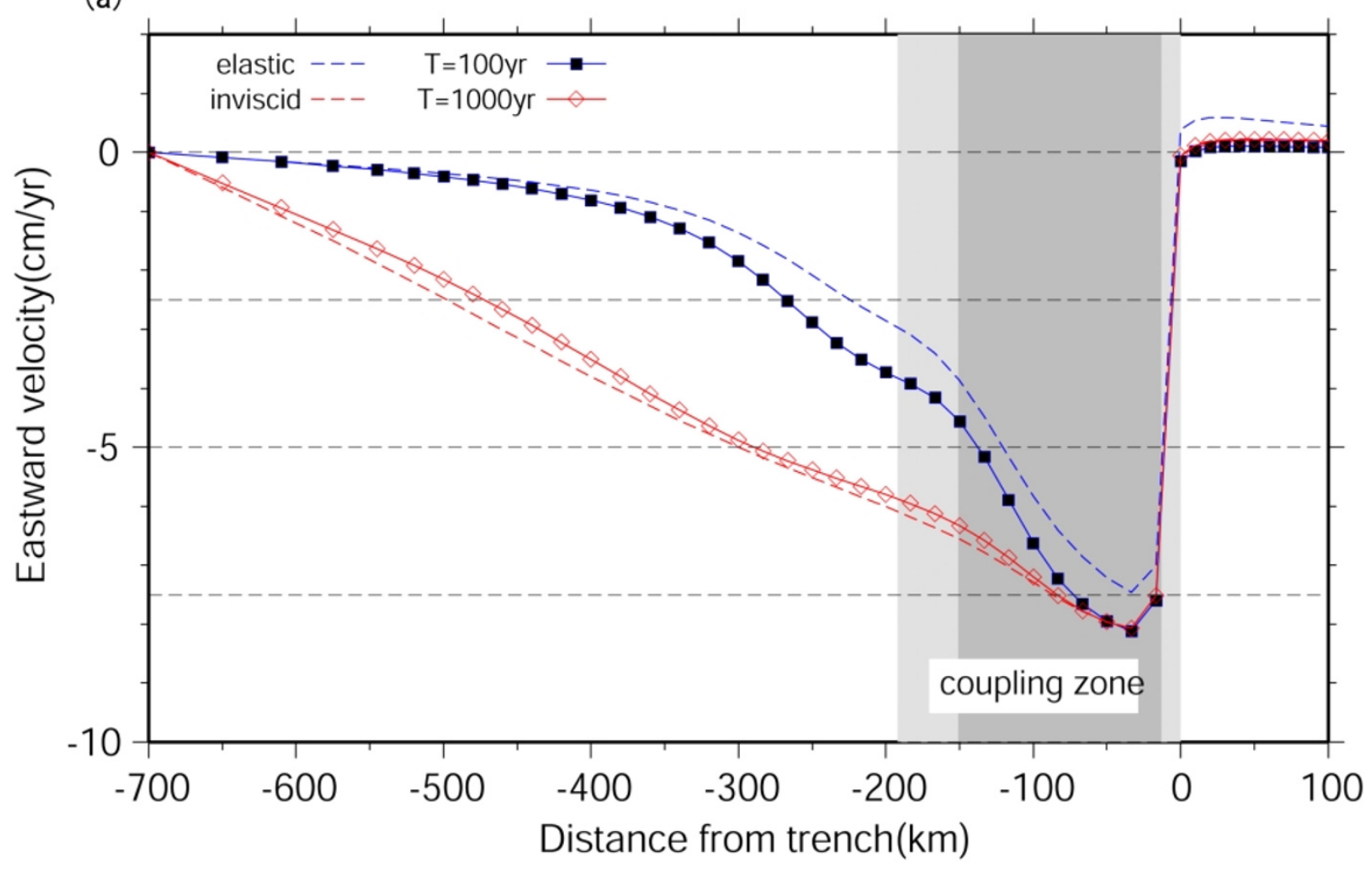

(b)

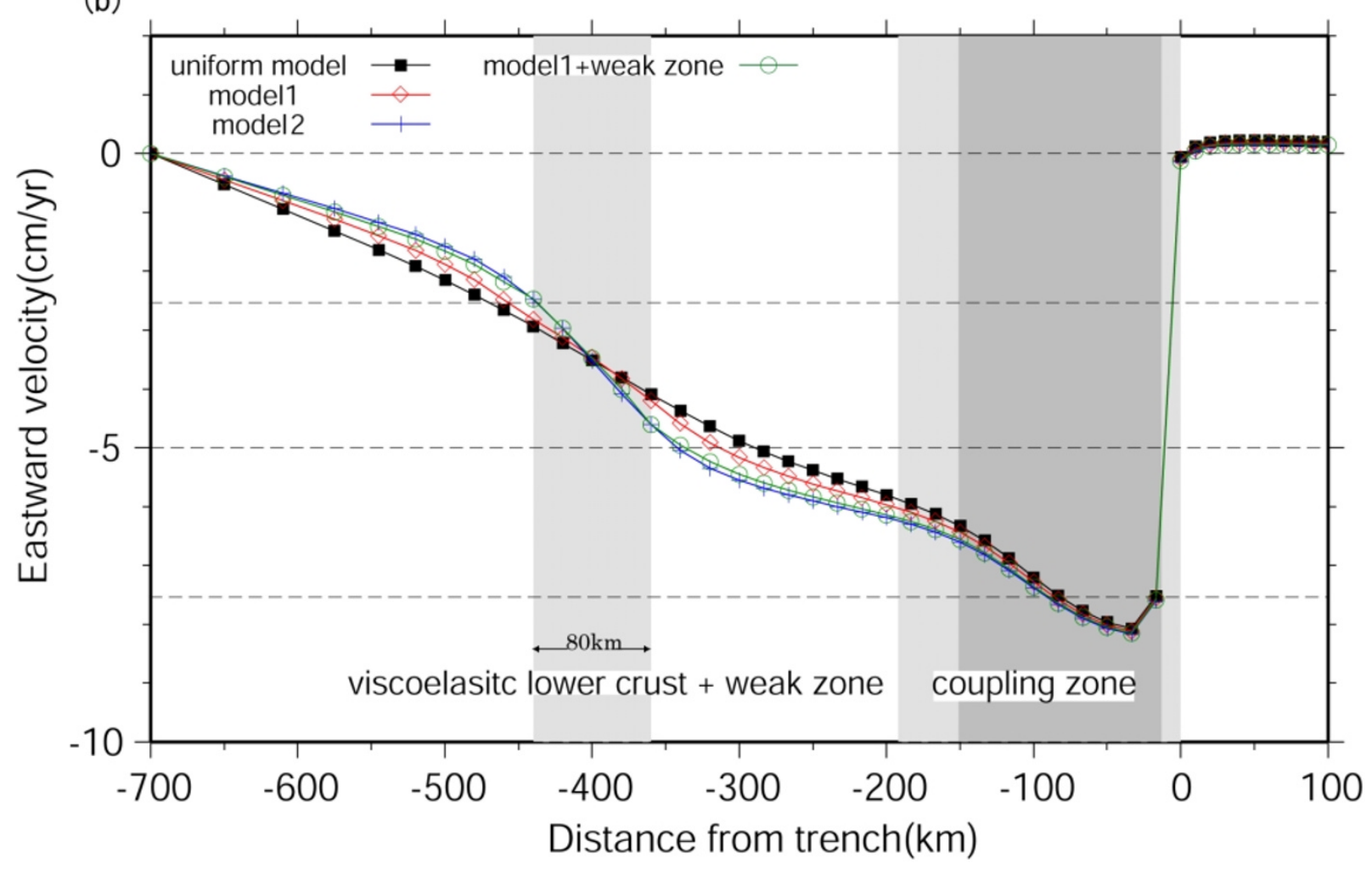

Fig. 4. Pro les of horizontal velocity at the surface. (a) Pro les for the different earthquake cycles, $T$. The blue line with solid squares indicates the horizontal velocity pro le at 60 years after the previous earthquake for $T=100 \mathrm{yrs}$, and the red one with open diamonds does at 900 years after the previous earthquake for $T=1000 \mathrm{yrs}$. The dotted blue and red lines denote the horizontal velocity pro les in case of the purely elastic mantle and the inviscid mantle, respectively. (b) Pro les of horizontal velocity at the surface during a later stage of an earthquake cycle in case of $T=1000$ years for crustal models with different crustal thicknesses and the weak upper crust. The red line with open diamonds and the one with crosses indicate the horizontal velocity pro les for Models 1 and 2. The pro le in the uniform crust model is shown by the black line with squares. The green line with open circles indicates the pro le for Models 1 with the weak upper crust. 



Fig. 5. (a) GPS horizontal velocity vectors in central Japan with respect to AM and the three sub-regions where the GPS velocities are plotted, separately, according to Iio et al. (2002). The origin in each profile is shown by the line between $\mathrm{O}$ and $\mathrm{O}^{\prime}$. (b)-(d) Comparison of the calculated velocity profile with the observed one for each sub-region shown in Fig. 5(a). In (A) Southern Tohoku region, the velocity profile is fitted by the result from viscoelastic model with shorter earthquake cycles $(T=100 \mathrm{yrs})$, and "plate coupling ratio" is about 0.8 , and the horizontal profile is almost approximated by the purely elastic model. In (B) Northern and (C) Southern Kanto regions, the profiles are calculated for viscoelastic Model 1 including the weak upper crust beneath NKTZ with the "plate coupling ratio" of 0.45 . 
has very low viscosity, a belt of large strain rates will be formed in the later stage of an earthquake cycle there. To con $\mathrm{rm}$ this, we introduce local viscoelastic structures into the crust in our FEM model as shown in Figs. 2(c) and 2(d), following Iio et al. (2002). The subdivisions shown by green rectangles in Figs. 2(c) and 2(d) represent the local viscoelastic lower crust assumed to have the same viscosity as the upper mantle. Models 1 and 2 have the elastic upper crust with the thickness of $15 \mathrm{~km}$ and $5 \mathrm{~km}$ beneath NKTZ, respectively. The calculated surface velocity pro les in the later stage of an earthquake cycle are shown in Fig. 4(b). The solid black line with solid squares shows the resultant pro le due to the uniform crustal thickness model at 900 years after the previous earthquake, and the red and blue lines show the pro les at the same time in cases of Models 1 and 2, respectively. In the case of the uniform model, the crust uniformly contracts as shown in the previous section. On the contrary, the surface strain rates just above the local viscoelastic lower crust in cases of Models 1 and 2 are larger than those in the surrounding regions. Since the viscoelastic asthenosphere does not resist the shear distortion, the deformation of the crust is well approximated by the deformation of thin elastic sheet with the heterogeneous thickness. In this case, the ratio of strain rates within the elastic crust for the different thicknesses is apparently determined by the ratio of the crustal thicknesses assuming the equilibrium of force.

Resultant strains above the weak zone in Model 2 are several times as large as in the surrounding region, which is consistent with the characteristics of the observed strain rate eld. Many large inland earthquakes, however, initiated at a depth of about $15 \mathrm{~km}$, and the cut-off depth of microseismic activity in the crust is also around this depth. Thus, even in NKTZ, the material down to a depth of $15 \mathrm{~km}$ must be brittle, and Model 2 dose not seem to be realistic.

4.3 Effect of the rigidity of upper crust beneath NKTZ

Koike (2002, personal communication) indicated a possibility that the upper crust down to a depth of $15 \mathrm{~km}$ beneath NKTZ has a lower seismic velocity, which is $70 \sim 80 \%$ smaller than that in the surrounding region, from the traveltime analysis of 'the 2001 Tokai explosion survey'. Following this velocity model, we assume the upper crust beneath NKTZ, which is shown by a bold rectangle in Fig. 2(c), has a low rigidity with $50 \%$ of that in the surrounding crust. This weak upper crust may be caused by the repeated failures due to the inland earthquakes there. The green line with open circles in Fig. 4(b) shows the calculated surface velocity pro-

les for Model 1 including weak upper crust. Similar to the results in the previous section, the resultant strains due to the changes in the rigidity of upper crust beneath NKTZ is easily understood from the force balance of the thin elastic crust, and the effect of the rigidity on the crustal strain rate

eld is almost the same as one of the crustal thickness. Even Model 1, if including the weak upper crust, predicts surface strain gap with the several times larger strains in NKTZ than those in the surrounding regions, as shown in Fig. 4(b).

\subsection{Comparison with the observed data}

Finally, we compare the calculated optimal velocity prole with the observed one, and estimate the "plate coupling ratio" of PA/AM interaction. Figure 5(a) shows the horizontal velocity vectors relative to AM around the central
Japan, which are obtained from GEONET observations. Following Iio et al. (2002), we divide the central Japan into 3 sub-regions, (A) southern Tohoku, (B) northern Kanto and (C) southern Kanto. Then, we draw distance vs. velocity plots for each sub-region (A)-(C) in Figs. 5(b)-5(d). We set the origin of the distance perpendicular to the trench axis at the O-O' line in Fig. 5(a), which is parallel to the axis of NKTZ. Then, NKTZ is located at the same distance at every 2-dimensional section perpendicular to the trench axis, while the trench axis is not. In Tohoku, repeated interplate earthquakes occurred with the recurrence interval of $\sim 100$ years or shorter (Ohtake, 1999), and the most recent interplate earthquakes near (A) southern Tohoku is the 1938 Shioyazaki-oki earthquakes as previously mentioned. Hence, we $t$ the observed data in (A) using the prole shown by the solid blue line in Fig. 4(a). The resultant "plate coupling ratio" in off-shore Southern Tohoku is about 0.8 , and is almost full interseismic locking if we $t$ using the purely elastic model (dotted blue line in Fig. 4(a)). On the contrary, the observed velocity pro le in northern Kanto and southern Kanto is explained by the pro le of the viscoelastic model including the viscoelastic lower crust with low viscosity and the weak upper crust with a thickness of $15 \mathrm{~km}$ (solid green line in Fig. 4(b)). Several trial calculations indicate that the suitable "plate coupling ratio" of PA/AM interaction is about $0.4 \sim 0.5$ as understood from Figs. 5(c) and 5(d). As mentioned above, NKTZ in Kanto district is located far from the trench than the weak zone in our FEM model. Hence, the inclusion of 3-dimensional con guration of NKTZ may predict smaller velocities at NKTZ, if the same plate convergence velocity $(9 \mathrm{~cm} / \mathrm{yr})$ is imposed. In such a case, the coupling ratios have to be larger than that estimated in this study. In Fig. 5(d), the large changes in the observed velocities at the distance $50-150 \mathrm{~km}$ correspond to the subduction of PH along the Suruga and Sagami trough, which is not considered in this study. As shown in this gure, the inclusion of the subducting PH changes the velocity eld only in the region close to troughs, but not in the inland region.

\section{Conclusions}

The crustal deformation velocities in central Japan have been simulated through viscoelastic FEM modeling including the great interplate earthquakes with different cycles, and the effect of local viscoelastic structure beneath NKTZ. The results are as follows:

1) It has been proposed that the elastic crust over the relaxed upper mantle can produces stationary stress eld in inland region due to the plate coupling force on the geological time scales (Wang and Suyehiro, 1999). In addition to this, we propose that deformation of an inland area also responds to the earthquakes cycles, and that the effect of earthquake cycles produces the longrange transmission of stress or strain rate at the later stage of cycles if the earthquake cycle is several times longer than the relaxation time of the viscoelastic system.

2) As schematically shown by Iio et al. (2002), the existence of the local crustal structure beneath NKTZ enhances the concentration of high strain rates in case of 
the viscoelastic model. Several trial calculations indicate that the suitable crustal structure beneath NKTZ is composed of the viscoelastic lower crust with the thickness of $15 \mathrm{~km}$ having almost the same viscosity at the upper mantle, and weak upper crust with half rigidity of the surrounding crust.

3) The "plate coupling ratio" $(0.4 \sim 0.5)$ between PA-AM and local crustal heterogeneity beneath NKTZ explain the large strain rate belt of NKTZ if the earthquake cycle offshore Kanto is long.

Acknowledgments. We thank Yoshihisa Iio and Kelin Wang for carefully reviewing the manuscript. This study is nancially supported by 'Earth Simulator Project' of Ministry of Education, Culture, Sports, Science and Technology (MEXT), and 'Spacial Project for Earthquake Disaster Mitigation in Urban Areas' of MEXT.

\section{References}

Hashimoto, M., Average horizontal crustal strain rates in Japan during interseismic period deduced from geodetic surveys (Part 1), Zisin (J. Seism. Soc. Japan), Ser. 2, 41, 13-26, 1990 (in Japanese with English abstract). Hashimoto, M. and D. D. Jackson, Plate tectonics and crustal deformation around the Japanese islands, J. Geophys. Res., 98, 16149-16166, 1993.

Heki, K. and S. Miyazaki, Plate convergence and long-term crustal deformation in central Japan, Geophys. Res. Lett., 28, 2313-2316, 2001.

Henry, P., S. Mazzotti, and X. Le Pichon, Transient and permanent deformation of central Japan estimated by GPS, 1, Interseismic loading and subduction kinematics, Earth Planet. Sci. Lett., 184, 443-453, 2001.

Huzita, K., Role of the median tectonic line in the Quaternary tectonics of the Japanese islands, Memoirs of the Geological Society of Japan, 18, 129-153, 1980 (in Japanese).

Iio, Y., T. Sagiya, Y. Kobayashi, and I. Shiozaki, Water-weakened lower crust and its role in the concentrated deformation in the Japanese islands, Earth Planet. Sci. Lett., 203, 245-253, 2002.

Iizuka, M., D. Sekita, H. Suito, M. Hyodo, K. Hirahara, D. Place, P. Mora, O. Hazama, and H. Okuda, Parallel simulation system for earthquake generation: fault analysis modules and parallel coupling analysis, Concurrency Computat.: Pract. Exper., 14, 499-519, 2002.

Ishikawa, N. and M. Hashimoto, Average horizontal crustal strain rates in Japan during interseismic period deduced from geodetic surveys (Part 2), Zisin (J. Seism. Soc. Japan), Sec. 2, 52, 299-315, 1999 (in Japanese with English abstract).

Mazzotti, S., X. Le Phichon, P. Henry, and S. Miyazaki, Full interseismic locking of the Nankai and Japan-west Kurile subduction zones, An analysis of uniform elastic strain accumulation in Japan constrained by permanent GPS, J. Geophys. Res., 105, 13159-13177, 2000.

Mazzotti, S., P. Henry, and X. Le Pichon, Transient and permanent deformation of central Japan estimated by GPS, 2. Strain partitioning and arc-arc collision, Earth Planet. Sci. Lett., 184, 455-469, 2001.

Melosh, H. J. and A. Raefsky, A simple and ef cient method for introducing faults into nite element computation, Bull. Seismol. Soc. Am., 71, 13911400, 1981.

Ohtake, M., Statistical Forecast of the Next Miyagi-Oki Earthquake, and Inter-Plate Coupling at the Focal Area, Abstr. Seism. Soc. Jpn., P031, 1999 (in Japanese).

Sagiya, T., S. Miyazaki, and T. Tada, Continuous GPS array and presentday crustal deformation of Japan, Pure Appl. Geophys, 157, 2303-2322, 2000 .

Sato, K., H. Ishii, and A. Takagi, Characteristics of crustal stress and crustal movements in the northeastern Japan arc (Part 1), Zisin (J. Seism. Soc. Japan), Ser. 2, 34, 551-563, 1981 (in Japanese with English abstract).

Savage, J. C., A dislocation model of strain accumulation and release at a subduction zone, J. Geophys. Res., 88, 4984-4996, 1983.

Suito, H. and K. Hirahara, Simulation of postseismic deformation caused by the 1896 Riku-u earthquake, Northeast Japan: Re-evaluation of the viscosity in the upper mantle, Geophys. Res. Lett., 26, 2561-2564, 1999.

Wang, K. and K. Suyehiro, How does plate coupling affect crustal stresses in Northeast and Southwest Japan?, Geophys. Res. Lett., 26, 2307-2310, 1999.

Wang, K., J. He, H. Dragert, and T. S. James, Three-dimensional viscoelastic interseismic deformation model for the Cascadia subduction zone, Earth Planet Space, 53, 295-306, 2001.

Zienkiewicz, O. C. and Y. K. Cheung, The Finite Element Method in Structural and Continuum Mechanics, McGraw-Hill, New York, 1967.

M. Hyodo (e-mail: hyodo@jamstec.go.jp) and K. Hirahara 